\title{
Dos Dramas de Narciso: reflexões antropológicas a partir de uma etnografia de um Serviço de Atendimento Móvel de Urgência (SAMU) de João Pessoa - PB
}

\author{
Elisa Pinto Seminotti ${ }^{1}$ \\ Secretaria Municipal de Saúde de João Pessoa, PB, Brasil \\ E-mail: elisaseminotti@hotmail.com \\ Ednalva Maciel Neves² \\ Universidade Federal da Paraíba, PB, Brasil \\ E-mail: ednmneves@gmail.com
}




\section{Resumo}

O estudo traz um recorte reflexivo a partir do trabalho de campo realizado na sede do SAMU Regional de João Pessoa, na Paraíba. A intenção é contribuir para a reflexão antropológica tomando o domínio dos serviços de saúde como territórios promissores para compreensão das relações sociais relacionadas às profissões, da instituição da saúde e das relações com os usuários. A singularidade do estudo está em focalizar as relações profissionais num serviço móvel de atendimento às chamadas urgências, de modo que foram problematizados as experiências dos profissionais, os desafios e as relações hierarquizadas para responder às "ocorrências". O texto apresenta, num primeiro momento, elementos sobre o trabalho de campo e o contexto da pesquisa e, num segundo momento, algumas reflexões sobre as relações entre as profissões que ali se encontram, envolvendo elementos relativos à formação das categorias profissionais, tensões e conflitos inerentes à ação assistencial e à rotina de trabalho, assim como alguns elementos da interação com a população que demanda o serviço.

Palavras-chave: SAMU. Serviço de Saúde. Etnografia. Antropologia da Saúde.

\section{Abstract}

This study aims to bring a reflexive image based on a field work in the headquarter of the regional SAMU of João Pessoa, in Paraiba, Brazil. Therefore, the intention is to contribute to the anthropological reflection by perceiving the dominance of the social services as a promising territory to the comprehension of the social relations related to the professions, the health institutions and the relations with the users. The singularity of this study focus on the professional relations on a mobile urgency attending service so that it discusses the experiences of the health professionals, their challenges and the hierarchized relations to answer to the occurrences. Firstly, this paper presents elements of the field work and the context of the survey, then, some reflections about the relations between the professionals in that scenario will be introduced. These reflections involves elements relatives to the formation of the professional categories, tensions and conflicts inherent to the attendance action and work routine, also including elements of interactions with the population that demands this service.

Keywords: Health Service. Service Mobile Emergency. Ethnography. Health Anthropology. 


\section{Introdução}

廿 ste texto apresenta algumas reflexões sobre o universo das relaÇões profissionais num serviço de saúde de urgência, comumente chamado de SAMU ( sigla que significa Serviço de Atendimento Móvel de Urgência), a partir de uma abordagem etnográfica ${ }^{3}$. Cabe ressaltar que as etnografias que se debruçam sobre os serviços de saúde públicos como universos particulares ainda são escassas (serão citadas em breve). No entanto, o campo é muito fértil, de forma que este trabalho traz à tona esse terreno de pesquisa como um lugar interessante para a pesquisa antropológica, possibilitando, inclusive, a exploração das tensões intrínsecas ao encontro antropólogo - serviço de saúde no texto etnográfico. A "análise de sistemas de cuidado e o acesso aos eles" tem se tornado um dos campos de investigação mais promissores para as ciências sociais, na medida em que desvenda o caráter simbólico que a saúde tem representado em diferentes contextos societários contemporâneos. (Herzlich, 2005)

O estudo sobre urgências e emergências, seus atores, seu funcionamento e seus usuários é bastante difundido no Brasil e fora dele, assim como também não é algo novo em termos de literatura científica da saúde 4 (Giglio-Jacquemot, 2005); pouco menos encontra-se especificamente sobre os serviços de urgências móveis, no qual se situa o SAMU. No entanto, é um tema que muito interessa porque tem um apelo grande, ao afetar praticamente todos (grande parte da população já necessitou algum dia de um serviço de urgência), e porque muito também do que se fala parte de "críticos", e não apenas de pesquisadores. Em se tratando da antropologia, é importante lembrar-se de que são poucos os estudos que envolvem uma etnografia do serviço 
de saúde ${ }^{5}$ e, menos ainda em um serviço de atendimento móvel ${ }^{6}$, uma tendência antropológica mais contemporânea que busca incluir os profissionais na condição de nativos.

A discussão das relações sociais e os elementos inerentes a elas observadas na etnografia foram fundamentados em autores da sociologia e da antropologia, além de debatedores da área da saúde, como C. Dejours, P. Bourdieu, E. Freidson, M. H. Machado, C. Dubar, A. Perrusi, M. Peduzzi e Deslandes, que contribuem para a reflexão sobre conflitos em espaços de trabalho multidisciplinar, que muitos deles se utilizam de bases sociológicas para o debate. Para discutir a experiência etnográfica, foram utilizadas as ideias de autores clássicos e contemporâneos, como B. Malinowski, Levi-Strauss, J. Clifford, C. Geertz, C. Rodrigues Brandão, R. DaMatta, M. Goldman e Víctora, Knauth e Hassen.

O SAMU, serviço que será descrito, é definido pelo Ministério da Saúde (Brasil, 2002) como o serviço que se propõe a chegar precocemente à vítima, logo após ter ocorrido o agravo - que possa levar a sofrimento ou sequelas, até morte - prestando atendimento e/ou transporte adequado para um serviço do Sistema Único de Saúde (SUS). Esse atendimento pode ser considerado primário, quando o pedido de socorro vem de um cidadão, ou secundário, quando um outro serviço de saúde o solicita. Os casos atendidos pelo serviço são imprevistos e demandam uma intervenção rápida, sem necessariamente ter caráter de gravidade, risco ou perigo (Giglio-Jacquemot, 2005). Em termos gerais, pode-se dizer que o objetivo do SAMU é prestar atendimento e/ou transporte adequado às pessoas que o solicitam, procurando ir até elas de forma mais rápida, após ocorrer algum agravo a sua saúde.

Conforme dito anteriormente, a solicitação do serviço pode ser realizada por um cidadão ou por outro serviço de saúde. Ambos acionam o serviço por ligação ao telefone gratuito 192, a qual é recebida por uma central de atendentes - os Técnicos Auxiliar de Regulação Médica (TARM) - que repassam a ligação para os médicos que fazem a avaliação da situação com o "solicitante". Após essa avaliação, será acionada ou não uma ambulância para o local necessário.

A peculiaridade do serviço do SAMU consiste no fato de que ele é muito visível para a população e a mídia em geral, por estar presente no 
momento dos acontecimentos, tratando de salvar vidas ou de minorar as consequências do que tenha ocorrido para as pessoas. $\mathrm{O}$ fato de ir ao encontro das ocorrências é uma singularidade frente aos demais serviços, tanto porque implica desde o fato da decisão do médico que atende a ligação, de acionar a ambulância ou não, ao atendimento propriamente dito, realizado na rua, na casa das pessoas, em espaços públicos. Essa possibilidade de decidir em enviar socorro e depois, de conseguir ou não realizá-lo, gera na população, e na sociedade, sentimentos contraditórios, de heróis a vilões, dependendo do desfecho. Apesar de algumas similaridades com locais que oferecem atendimento de urgência, como hospitais de trauma, uma importante diferença é que neste último existe uma possibilidade de manter a atuação dos profissionais em ambiente não acessível à população, portanto, menos vulnerável à "participação" desta na hora do atendimento.

É importante indicar que, assim como outros territórios de pesquisa, a familiaridade com os elementos nativos é a tônica do trabalho do pesquisador. No SAMU não houve diferença, e certos aspectos como a vestimenta, a "língua" (o "alfabeto do Q" - linguagem utilizada na comunicação entre profissionais através de rádio transmissão), a rotina, os conflitos interpessoais e entre categorias profissionais, bem como a interação do serviço com a população que o demanda, foram sendo observados e trazidos para a compreensão como elementos reveladores da complexidade que envolve a inserção do pesquisador em um serviço da área "biomédica".

Aqui, também, o desafio enfrentado pelos pesquisadores que tem formação ou que atuam na área da saúde (ambos representam as autoras deste texto ${ }^{7}$ ) consiste em garantir o estranhamento e a alteridade com o grupo pesquisado, correndo-se o risco de proceder a uma naturalização dos fenômenos estudados. Na experiência aqui relatada, a superação desse desafio esteve associada a uma postura problematizadora das situações observadas no campo, a partir de uma constante revisão crítica no ato de registro e análise das observações e interações vivenciadas no trabalho de campo. Exercício realizado desde o "período de contaminação", no sentido de Brandão (2007), como aqueles momentos que caracterizam um período de entrosamento do 
pesquisador com as pessoas, consistindo nas relações pessoais com os interlocutores.

Outra perspectiva importante adotada consistiu em manter uma postura reflexiva baseada nos movimentos contínuos de "[...] vaivém entre o 'interior' e o 'exterior' dos acontecimentos [...]", conforme Clifford (1998, p. 33), de forma que se possam absorver as especificidades daquilo que se vivencia e ao mesmo tempo dar um passo para trás e poder situar essas especificidades em contextos ampliados. Assim, parte-se da concepção de que o enfoque etnográfico se debruça sobre o estudo de um grupo de pessoas para compreender como elas veem o mundo e organizam seu cotidiano, objetivando descobrir a "perspectiva do ator" (Helman, 2003, p. 21). Para tanto, a observação participante, como ferramenta da etnografia, possibilita o exercício de uma dialética entre experiência e interpretação que provê significados profundos para acontecimentos singulares.

Uma questão relevante observada no trabalho de campo foi a diferença entre o que Fleischer (2001) chama de práticas on-stage ${ }^{8}$ que se consegue assistir em visitas técnicas ou ao conhecer os sujeitos em eventos sociais, através da formalidade que se oferece aos estranhos -, e a performance off-stage, somente visualizável e vivenciada quando se consegue passar pela barreira de pessoa de fora e alcançar as configurações e processos que o grupo estudado estabelece no seu cotidiano. Por isso, considera-se que por meio da etnografia foi possível acessar o funcionamento interno do SAMU e as relações sociais que ali se dão, revelando conflitos, relações de hierarquia e de jogos de interesses que estão implicados no objetivo central do SAMU "salvar vidas" - tal como é expresso pelos profissionais do serviço. E percebeu-se que aquilo que se mostra tão louvável para alguns - o trabalho propriamente dito, ou seja, o trabalho de "salvar vidas" -, ou por sua característica de trabalho humano, também, gera rivalidades e jogos de poder envolvendo classes profissionais e formas de inserção no trabalho cotidiano.

De fato, o "salvar vidas" evocado pelos profissionais implica numa responsabilidade social importante, visto que esses profissionais atuam em circunstâncias críticas na vida das pessoas. São situações 
marcadas por tensões envolvendo a vida e a morte, de modo que decisões precisam ser tomadas e intervenções adotadas em curtíssimo período de tempo, após uma avaliação da situação encontrada. Esses elementos exigem: competência, destreza, rapidez e coordenação entre profissionais, seja para os que estão na chamada "base", seja entre os que atendem a um chamado.

Dessa forma, este texto está construído a partir de dois elementos: o primeiro descreve a metodologia e o contexto da pesquisa de forma a situar o leitor nas questões que se apresentam em seguida; $\mathrm{e}$, a segunda parte, intitulada "Narciso no espelho d'agua", traz algumas reflexões sobre as relações entre as profissões que ali se encontram, envolvendo elementos relativos à formação das categorias profissionais, tensões e conflitos inerentes à ação assistencial e à rotina de trabalho, assim como alguns elementos da interação com a população que demanda o serviço.

\section{SAMU: sobre a observação e o contexto da pesquisa}

Esta reflexão se baseia num trabalho de observação realizado durante sete meses no Serviço de Atendimento Móvel de Urgência (SAMU) de João Pessoa - PB, variando-se os turnos da observação (porém, não foram observados plantões noturnos) de, em média, quatro horas. O lugar da observação é chamado de "base" do SAMUJP, pois é onde fica a "central de regulação", portanto, "o coração" do SAMU, no qual são recebidos os pedidos de atendimento e estabelecidas estratégias de prestação de cuidado, incluindo as garagens onde as ambulâncias ficam à espera das "ocorrências". Nesse local, concentra-se, também, todo o trabalho administrativo que o serviço exige, envolvendo o arquivamento das requisições, manutenção e organização de materiais, medicamentos e aparelhos, almoxarifado, organização dos veículos e atendimento à população, estudantes, pesquisadores e fornecedores.

Durante o período de observação, adotou-se a observação participante, entendida no sentido de Brandão (2007), em que o adjetivo participante consiste no exercício de "estar ali", no cotidiano do serviço, observando e compreendendo - rondando por todos os setores, 
questionando, entendendo a rotina de cada um - e, também, pelo envolvimento pessoal quando possível - discussão com os profissionais sobre o serviço e a rotina, mas também tempo de descontração, risadas e conversas banais, e de envolvimento em atividades que fossem coletivas.

Não para sentir, não para que as pessoas me sintam como alguém deles, mas que para esse participar faça com que eu me identifique mais de perto como uma pessoa não deles, mas mais próxima deles. (Brandão, 2007, p. 14, grifos nossos)

Os profissionais que compõem o serviço e que foram os interlocutores desta etnografia são profissionais de diferentes categorias da área da saúde, de uma maneira geral, mas também se encontram outras categorias que são encontradas no SAMU, em razão do tipo de atendimento ofertado. Assim, além de médicos, enfermeiros, técnicos de enfermagem, foram encontrados: condutores socorristas, rádio operadores, TARMs e, como dito, coordenadores e pessoal administrativo e de manutenção. As equipes nas ambulâncias são compostas segundo a capacidade destas: as ambulâncias avançadas (chamadas USA Unidade de Salvamento Avançado), que funcionam como pequenas UTIs; são formadas por médico, enfermeiro e condutor socorrista. As ambulâncias mais simples, que fazem um primeiro atendimento (chamadas UBS - Unidade Básica de Salvamento), são compostas por técnicos de enfermagem e condutor socorrista.

Nesse contexto, a "contaminação" proposta por Brandão é complexa e, em um primeiro momento de chegada ao serviço, para quem nunca esteve lá, tem-se a impressão de estar em outro país (ou planeta), apesar da proximidade que se tem com a área da saúde, em razão do objetivo do serviço que exige outra configuração para as práticas profissionais. Para o neófito, os profissionais do SAMU se assemelham aos nativos de pesquisas etnológicas, de tribos desconhecidas. "A sensação é de que nunca se virá a atingir uma comunicação fluente com os nativos [...]" (Malinowski, 1984, p. 20), dizia o autor quando se referia ao idioma complicado das ilhas da Nova Guiné. Pode-se dizer que em algum nível essa também foi a impressão no campo estudado. Pode 
parecer exagero, mas ao caminhar pelos corredores, vendo inúmeras pessoas passando (algumas correndo), todas vestidas igualmente, com macacões cheios de "parafernálias", sons de pessoas conversando, telefones tocando e rádios comunicando simultaneamente em vários locais, como um tipo de eco, é fácil sentir-se um estrangeiro.

Mesmo que a linguagem médica seja "familiar" ao pesquisador, é fácil perder-se na comunicação utilizada no SAMU. Um dos canais de fala é a linguagem do "Q", usada por instituições que se comunicam via rádio; lá, ainda se pode dizer que ela é utilizada com o objetivo não apenas de garantir a comunicação entre as equipes com outras equipes e com a base, mas também para transmitir informações que interessam aos profissionais de forma a evitar que o "usuário" e seus familiares tomem conhecimento do conteúdo das mensagens, principalmente em circunstâncias críticas. Sem um treinamento sobre a linguagem e uma prática cotidiana, é praticamente impossível compreender o que está sendo falado. Esse foi um exercício que as pesquisadoras fizeram, de forma a entender, inclusive, as piadas.

Em termos dos horários do serviço, os turnos de trabalho são os mesmos para os profissionais de saúde, TARMs, rádio operadores, mecânicos e pessoal de limpeza, ou seja, plantões de 12 horas (que começam às sete da manhã e às sete da noite). Somente o pessoal administrativo, trabalha em horário comercial. Cada plantão está formado pela quantidade de profissionais necessária para que todas as ambulâncias tenham suas equipes completas, além do número de TARMs e de rádio-operadores que é fixa por plantão.

O estranhamento e a dinâmica do serviço exigiram a adoção da postura metodológica chamada de "busca ativa" das pessoas, na medida em que ocorrem diferentes estratégias para aproximação e abordagem dos profissionais. Assim, pelas dificuldades de iniciar uma interlocução num contexto desconhecido ao pesquisador, mas também em razão do próprio sistema de trabalho do serviço que se realiza "por plantões", adotou-se uma estratégia de inspiração na chamada técnica snowball, buscando, a partir do contato inicial com um profissional, estender o processo de conhecimento e interação para outros profissionais que se dirigiam a essa pessoa, seja por questões relativas ao serviço, seja por curiosidade com a pesquisadora. Essa prática passou 
a ser adotada cotidianamente, tendo em vista que a cada dia tinha-se uma equipe de profissionais diferente atuando no serviço. Depois de algum tempo, ao chegar ao serviço procurava-se inicialmente uma pessoa conhecida, e na conversa (direcionada ou informal) investigava sobre as pessoas que passavam próximo, que cumprimentavam esse profissional, ou esperava aproximação daqueles que vinham conversar com esse interlocutor imediato.

Cabe ponderar que se trata de um contexto em que o saber médico predomina e as relações permanecem dependentes deste saber, na medida em que o médico centraliza as decisões a serem tomadas e de forma imediata. Mesmo nesse contexto, os profissionais de saúde não médicos e os pacientes lidam com a luta pela legitimação do seu discurso perante o médico, buscando inserir suas interpretações sobre os acontecimentos no contexto da avaliação médica.

Uma última ponderação diz respeito ao fato de que este conhecimento biomédico dominante do campo de pesquisa é tomado também como um elemento que integra a investigação e deve ser considerado em razão do seu caráter constituinte para o universo da saúde. Para Sarti (2010), o antropólogo inserido nesse contexto, trata de aplicar o método etnográfico, buscando compreender as regras e normas, linguagens e interpretações, intervenções, conflitos e disputas.

\section{Narciso no Espelho D'água}

O mito de Narciso conta a história de um jovem que, ao olhar seu reflexo na água, apaixonou-se de tal forma por si mesmo que morreu estagnado, sem conseguir reagir. Narciso morreu de forma trágica porque Nêmesis assim o condenou, movida pela feiura da alma de Narciso, que desprezava todas as mulheres que por ele se apaixonavam ${ }^{10}$.

Quem trabalha no SAMU, muitas vezes, vive de um reflexo perfeito, apaixonado pelo que o reflexo mostra. Por causa disso, é difícil conseguir entrar no "lago" para ver a faceta que está escondida lá dentro. E essa faceta nem sempre é bela, porque estão em jogo as idealizações do seu objetivo, envolvendo também relações interpessoais, interesses diversos, interações de diferentes ordens (entre profissionais, entre profissionais e usuários, de natureza administrativa, de práticas 
de saúde), tensões e conflitos, entre outros aspectos. O trabalho nas instituições de saúde implica a interação de diversos atores que carregam consigo os "[...] valores, símbolos e poderes relativos à saúde e à doença, à vida, à morte e às identidades profissionais. Estes atores formam uma complexa cultura organizacional". (Almeida, 2007, p. 78)

Essa experiência de Narciso à qual refere-se é uma alusão ao sentimento de orgulho presente nos profissionais que lá trabalham, sendo o que mantém muitos com o passar dos anos, apesar de dificuldades trabalhistas ou de relacionamentos. É muito comum que, ao serem perguntados sobre o motivo de atuar no SAMU, ouvir dos diferentes profissionais que eles se sentem bem, orgulhosos com seu trabalho. Alguns enfermeiros e técnicos de enfermagem relataram as dificuldades que tiveram que passar para conseguir a contratação do SAMU. Uma técnica de enfermagem uma vez relatou que "[...] 0 salário não é bom, mas todo mundo quer colocar esse macacão". As falas dos grupos de interlocutores sobre essa sensação se referem geralmente ao sentimento que salvar uma vida dá. A adoração do público vem em seguida. Contam contentes sobre as pessoas que os foram visitar na base depois ainda de anos de terem sobrevivido a algo, pessoas que levam cartas, que os reconhecem na rua. Segundo eles, essas coisas são as que fazem o trabalho realmente valer a pena e alimentar o desejo de permanecer trabalhando no SAMU, vestindo o macacão.

No entanto, o que a água esconde são conflitos interpessoais poderosos, nos quais prevalece a vaidade e a luta pelo poder. Isso se aplica também ao momento de atendimento e está diretamente relacionada ao que foi dito - se um profissional "aparece" mais do que o outro, ele ficará com o prêmio do salvamento. Em outro âmbito, o interno por assim dizer (na base, na hora da espera, na ambulância), essas disputas aparecem nas pequenas coisas, como o momento de descanso (que será relatado adiante), ou em questões relativas às decisões tomadas. É comum ver uma equipe voltando de um atendimento muito aborrecida com os outros colegas da ambulância ou com o pessoal que determina o envio de atendimento e conduta, pois, muitas vezes, essas condutas não são bem aceitas. Essas questões serão desenvolvidas de melhor forma a partir da descrição dos personagens desse "drama". 
Rodrigues, Alvaro e Rondina (2006) analisam a obra de Dejours trazendo seu conceito de teatro do trabalho, que se pode aplicar aqui. Cada indivíduo, na sua singularidade, vive os conflitos e as dificuldades de formas diferentes; esses acontecimentos incidem diretamente sobre o ambiente e processo de trabalho, criando um teatro no qual interagem os "personagens" (patrão, empregado, supervisor, colega de trabalho), com um "enredo" (a estrutura de poder e a hierarquia, preconceitos, valores), "o cenário" (o macroambiente, o desemprego, a instabilidade, as incertezas), e inclusive "espectadores" (família, amigos, adversários).

Quando se aplica o conceito de teatro de Dejours ao SAMU, os personagens são todos os profissionais de saúde (médicos, enfermeiros, técnicos de enfermagem e condutores socorristas), mais as coordenações e os técnicos administrativos, além da população, que se relaciona em um enredo no qual a força médica é soberana pelo próprio objetivo do serviço "salvar vidas", assim como a estrutura hierárquica que mantém o conjunto das relações sociais que ali se desenvolvem. No cenário tem-se todo o contexto das profissões e de como elas se encaixam na divisão do trabalho, e ainda, como o serviço do SAMU opera na rede de assistência à saúde. Em todo esse drama estão implicados valores, concepções pessoais e formas de relacionar-se que constituem o jeito de atuar no SAMU.

É possível começar então pelos personagens da nossa trama e como seus papéis se desenvolvem. A impressão que se tem é que a interação dos profissionais e técnicos no SAMU acontece sob a influência de uma "batalha" entre as diferentes classes profissionais. Os "times" são: o dos "superiores", divididos entre médicos e enfermeiros, sem, no entanto jogarem no mesmo time; e o dos "técnicos", formado pelos técnicos de enfermagem, os condutores, os trabalhadores administrativos e os TARMs, cada um no seu time também. Não se quer dizer com isso que não há relação entre os atores, no entanto, as relações pessoais acabam onde o "corporativismo" começa. Se algo "dar errado", como dizem, é sempre porque "os médicos" não querem sair logo para as ocorrências, ou porque "os enfermeiros" acham que tudo tem que ser feito por eles, ou então "os técnicos de enfermagem" 
são preguiçosos, "os condutores" não têm paciência - há sempre um dedo apontado para o outro.

É interessante notar como problemáticas relativas às relações entre profissões de saúde se reproduzem, mesmo que em contextos organizacionais diferentes, Machado (1995) analisa as profissões de saúde a partir de uma reflexão clássica durkheimana, para constatar que as corporações profissionais não têm um papel de mantenedores da ordem, consensuais e harmonizadoras. Pelo contrário, estão focadas na coletividade de pares, voltadas para questões políticas conflitivas e competitivas que dizem respeito aos interesses do grupo, mas que ganham contornos no cotidiano das relações entre profissões, através de disputa sobre práticas e direitos de cada grupo de profissionais.

Na observação de campo, um exemplo importante dessas disputas é a utilização de um espaço coletivo importante: os repousos. O descanso dos profissionais é motivo de brigas há muito tempo, e não parece ter fim. Os quartos de repouso já foram modificados estruturalmente para serem divididos entre os "técnicos" e os "superiores". Assim sendo, existe o repouso dos médicos e enfermeiros, e dos demais técnicos. Segundo alguns técnicos de enfermagem, a justificativa para essa divisão foi dada pelos "superiores", que diziam que os "técnicos" faziam muito barulho no repouso e não respeitavam o espaço, também embasado em uma questão de espaço, e de quantidade de camas insuficiente. No entanto, ainda há "superiores" dormindo no quarto dos "técnicos", justificando que os colegas (os "iguais") tampouco respeitam o espaço. Entre as mulheres, as médicas afirmam que "as enfermeiras se acham donas do espaço". Entre as próprias enfermeiras também há rixas por não respeitarem o silêncio. As "técnicas"11 deixam clara sua indignação por essas profissionais ocuparem seu repouso, já que se sentem expulsas do espaço anterior. Esses técnicos dizem que acham que elas preferem ir ao seu quarto porque "[...] se no quarto delas as colegas fazem zoada, elas não dizem nada; mas se estão no nosso e alguém diz um 'ai', elas já dão um grito com a gente, porque nós somos técnicas".

Antes de pensar que isso é uma tortura às "técnicas" e que as médicas e as enfermeiras são algozes, cabe salientar que os TARMs também passam por tais conflitos. Alguns comentaram que os "téc- 
nicos" acham que eles não devem ter direito a ficar no repouso, já que "[...] passam o dia inteiro sem fazer nada, só sentado atendendo telefone". A partir da repetição dos relatos é possível entender que os TARMs são técnicos que, exatamente por se movimentarem pouco e terem a rotina muito parecida, acabam tendo mais lesões corporais (por esforço repetitivo) e estresse psicológico. Além disso, cabe salientar que os demais profissionais, em todos os intervalos entre ocorrências (e isso pode durar 4, 5, 6 horas, dependendo do dia) podem descansar e dormir. Por isso, existe também uma atitude de revolta dos TARMs que, ao irem descansar na sua hora concedida, não conseguem dormir porque os demais "técnicos" (estende-se aos "superiores") usam o repouso para conversar, falar ao telefone, ou ficar no computador, o que interfere sobre seu descanso.

Dessa forma, o repouso é quase um laboratório onde todos os conflitos emergem, refletindo elementos do contexto estrutural da área da saúde. As relações hierarquizadas, o desrespeito para com o outro, o desconhecimento sobre o trabalho do colega, o convívio com as mesmas pessoas durante muitas horas por dia em situações de tensão são tensões cotidianas, mantidas a partir das diferenças inerentes ao domínio da saúde, despontando pelo clima de competição e jogos de poder. É como se estivessem dizendo: “[...] desse jeito, lembramos a cada um qual é seu lugar". É interessante analisar que esses acontecimentos são relatados aos coordenadores do serviço, porém sem que haja qualquer formalização desses "desrespeitos", o que poderia ser feito através de documento "escrito" ou "dando nomes aos bois".

Em prol de justificar os problemas e conflitos dentro do ambiente de trabalho, os "grupos" jogam-se uns contra os outros, sempre empurrando as responsabilidades para o outro, e mantendo, ao mesmo tempo, o corporativismo. Se acontecer um desentendimento, por exemplo, entre um técnico de enfermagem que diz estar seguindo as ordens de sua gerência (enfermeiro) e outro enfermeiro, este último pode discutir fervorosamente com o técnico, mas não se indispõe com o colega de classe que deu as ordens.

Pode-se refletir sobre essas situações na perspectiva do conceito de interações sociais preconizado por Goffman (1970), compreendendo 
que a influência recíproca entre atores que se encontram compõe um processo de interação que não se realiza somente pelo consenso, mas também pelo conflito. No caso do SAMU, os conflitos têm diferentes procedências, eles são tanto estruturais (relacionados à organização e hierarquização das profissões em saúde), quanto organizacionais (relacionados ao serviço, divisão de tarefas), interpessoais (das subjetividades) e também relativos às características da assistência que é prestada pelo serviço.

Nesse sentido, um aspecto marcante observado consiste nas diferenças encontradas nas relações entre os profissionais, se analisar do ponto de vista comunicacional (tendo como referência o agir-comunicativo $^{12}$ de Habermas). Compreende-se aqui que existem duas maneiras de agir: uma que se realiza quando o serviço é a referência, por exemplo: no momento da intervenção dos "casos" ou nas discussões na regulação, ou nos relatos individuais; e, outra, que desponta em momentos de recreação, quando questões técnicas relativas ao trabalho não estão em jogo. Nos primeiros, a comunicação que ocorre é basicamente técnica ou instrumental - um padrão restrito de comunicação que somente foca na instrumentalização da prática. No entanto, quando são observados os momentos de ócio, é evidente que os desafetos e as desavenças entram em stand by, e é como ver crianças ou adolescentes brincando. Os gritos são sempre altos, mas não de briga, e sim de incentivo ou comemoração durante os jogos.

As pessoas se unem em duplas de jogadores ou torcida para acompanhar os jogos. Em geral, na mesa de dominó, os quatro jogadores costumam ser dos mais variados; não há uma mudança de humor se um dos participantes se retira e entra um médico no seu lugar; sendo o mecânico ou o "doutor", homem ou mulher, novo ou antigo, as implicâncias são as mesmas, e as brincadeiras inerentes aos jogos ("agora chora! Perdeu!!", "esse não é de nada", "isso é roubo!") não mudam. É nesses momentos em que a comunicação ocorre, sem, no entanto haver agir-comunicativo. Isso porque essa forma de comunicação ocorre em caráter pessoal, focada na relação de amizade ou camaradagem entre as pessoas, sem sobressaltar as relações hierárquicas. A forma de se comunicar com o outro se dará a partir de como eu o vejo em termos de relação pessoal - se simpatizo com ele, me comunico, senão não. 
Por outro lado, cabe considerar que qualquer que seja a dimensão comunicacional, em termos técnicos ou pessoais, as equipes não se mostram capazes de articular as ações, colocar em discussão as intervenções, problematizar as dificuldades e conflitos. Quando fora da ambulância, na mesa de sinuca, a conversa com o "colega" é amigável, e cada um se porta com o outro conforme proximidade e simpatia. Já ao entrar na viatura, o condutor é o condutor, diferente do médico, que não tem como opinar sobre nada porque ele é condutor. A comunicação aí se dará somente com foco na técnica e na hierarquia existente, em termos de "passa um rádio para a central", "traga a maca", "feche a porta". Os lugares ocupacionais estão bem definidos. Porém, além da circunstância do "chamado", não existe um momento se reflexão das equipes sobre um problema ou sobre a atuação de cada um, nem mesmo uma interação técnica de aprendizagem.

É possível colocar em análise que esse estilo de comunicação também pode ser adotado como uma forma de mecanismo de afrontamento das tensões. As "ocorrências" trazem a atenção para o foco da atuação, e a preparação começa no caminho de ida. Esse momento mobiliza o habitus de cada profissional - no sentido de Bourdieu (2008) - trazido à tona, para fazer frente, e de forma coordenada, as exigências da "ocorrência". Seguindo o pensamento de Bourdieu, o habitus é concebido como esquemas ou disposições, socialmente construídos e adquiridos nas e pelas experiências práticas dos agentes. Ele, portanto, não é estático, pois se adapta e ajusta ao contexto social ${ }^{11}$. (Setton, 2002)

No contexto do SAMU que se está discutindo, o exemplo dos repousos ilustra o habitus se fazendo valer. Tudo aquilo que os profissionais viveram quando aprenderam a ser quem são fica evidenciado nas formas de interação. Em uma escala descendente em termos de hierarquia, os médicos "rebaixam" os enfermeiros, que o fazem com os técnicos, que o fazem com os TARMs e condutores, que muitas vezes o fazem com os técnicos administrativos. O habitus médico está fundamentado numa concepção hierárquica e socialmente diferenciada frente aos demais profissionais de saúde. Ao falarem dos enfermeiros, os médicos elaboram um discurso que tende a limitar a atuação desse profissional a uma ação de natureza simplória, essa estratégia 
discursiva voltada para afirmação de sua posição, aprendida desde os primeiros passos do curso de graduação nas instituições de ensino ${ }^{14}$ - essa atitude parte de uma incorporação progressiva do habitus, em que, antes mesmo de ser "doutor", já se adota uma atitude corporal de "superioridade" frente às outras profissões. (Sassi, 2012)

Na análise de Freidson (2009) acerca das profissões, o autor expõe a distinção entre profissões e ocupações. Para ele, a primeira é quase como uma evolução da outra: a profissão tem a característica de dominação na divisão do trabalho, e mantém um status por apresentar características de autonomia e autorregulação, sempre no intuito de convencer os demais de que existe uma confiança inabalável nos membros que fazem parte da categoria.

Partindo da concepção de Foucault (2009), acredita-se que o status de profissão também tem relação com a questão de poder e como ele se mostra através da produção e uso do saber. Nas instituições, a divisão do trabalho institui claramente dois territórios: o do saber-poder, que provê o lugar da competência, do conhecimento/reconhecimento, da verdade, da autoridade e da legitimidade; e o do não saber, caracterizado como lugar da exclusão, da desqualificação, é segregado e pode inclusive ser considerado como perigoso. Se analisar a profissão como o território do saber-poder e a ocupação como o não saber, do ponto de vista foucaultiano se justifica que essas ocupações se constituam historicamente como um campo que necessita sistematicamente de acompanhamento e controle. (Coimbra; Leitão, 2003)

No campo da saúde, essa divisão apresenta uma grande complexidade, em razão de que o "não saber" da atuação dos demais profissionais não médicos, tem uma implicação direta sobre o cuidado (ou assistência) a ser disponibilizada ao usuário. Além disso, não existe um "não saber" já que as práticas sociais e profissionais não fogem à regra, se fundamentam em um saber cotidiano, não acadêmico, porém legítimo socialmente. Essas questões aparecem na observação de campo em determinadas ocasiões. Assim, durante uma "ocorrência", os profissionais que fazem o atendimento, independentemente de quem eles sejam, são valorizados pela população, que deixam claro através de falas que se pôde ouvir, a gratidão por terem sido atendidas, 
aconselhadas e cuidadas. Mesmo não sendo o médico ali presente, os profissionais oferecem uma atenção fundamentada naquilo que sabem e que podem fazer no momento. Desde um conselho de como cuidar da pressão para que ela não se altere a indicações de como proteger a casa contra acidentes, quando atendem um idoso são práticas desse tipo.

Bourdieu (2008, p. 88) outorga à medicina um status superior que junto ao direito e à teologia seriam as faculdades ou disciplinas com mais poder frente ao Estado e à população, com a função de controlar seus usos práticos, assim como aqueles que usam seu saber. Este poder tem relação com questões simbólicas que não aparecem cotidianamente, mas que fundamentam as ações, como o valor do papel do médico e a capacidade de intervenção sobre os corpos. No caso dos demais "saberes", para Freidson (2009, p. 67), o poder foi reorganizado de forma a possibilitar à medicina que ela fosse administradora (consideradas do não saber, no sentido de "limitar, supervisionar ou dirigir" o exercício de atividades de consulta relacionadas a ela ${ }^{15}$.

As atividades paralelas de saúde são levadas a cabo pelos "outros" - que Freidson chama de paramédicos. Nestes se incluem todos os profissionais que atuam na saúde e que, como já se viu, estariam subordinados aos médicos. Não existe praticamente nenhuma atividade exclusiva que os médicos podem realizar que os paramédicos não possam ou saibam realizar; no entanto, não é isso que os diferencia.

O que o médico faz é parte de uma ampla divisão técnica do trabalho: uma parte às vezes muito genérica ou pouco definida. O que é bem definido é o controle que o médico exerce sobre a divisão do trabalho. (Freidson, 2009, p. 68)

No SAMU, foram frequentes os relatos de que os enfermeiros são os que realizam eficazmente a maioria dos procedimentos quando acionados na USA; no entanto, quem leva o "crédito" pelo atendimento são os médicos, mesmo quando eles só conseguem concluir as técnicas com a orientação do colega enfermeiro.

Um aspecto apontado é que raramente os enfermeiros são entrevistados pelos meios de comunicação, como a televisão, depois dos atendimentos ou das ocorrências, cabendo ao médico relatar ou comentar os "casos". Vale dizer que o "crédito" não é dado pelos próprios 
médicos ou pares, mas pela própria população, que vê nessa figura a personalização do salvamento.

No entanto, nesse contexto existe também uma dimensão simbólica das formas de dominação, possível de compreender a partir do conceito de campo de Bourdieu (1976). Esse conceito se constitui como espaço no qual estão estruturadas posições ou postos que se definirão conforme o lugar que ocupam neste espaço. Esse lugar não é analisado segundo as características individuais dos ocupantes, mas é determinado por elas. Dessa forma, o campo só se conforma como tal a partir da definição de objetos de desejo e disputa, que são específicos de cada campo; e para que haja disputa (e consequentemente, campo), é necessário que existam atores dispostos a disputar o jogo, " [...] dotados de habitus que impliquem no conhecimento e no reconhecimento das leis imanentes do jogo, dos objetos de disputas, etc." (Bourdieu, 1976, p. 2, grifos nossos. No trabalho do SAMU, a relevância e o poder concedido à categoria médica não fica no plano do "inconsciente coletivo", de cultura profissional, ou da divisão do trabalho. Ele é conferido pelo Estado sob a forma de organização do serviço, que, como visto anteriormente, deixa claro que o médico é o profissional que tomará todas as decisões concernentes à atuação dos demais profissionais.

No campo do SAMU, os atores já foram apresentados e existe a disposição de competir pelo objeto principal, que é o ato de determinar a conduta de "salvamento"; em última instância, a vida das pessoas. A dominação médica é outorgada pelo Estado, mas não sem disputa simbólica. Dentro da "viatura", o diálogo entre os profissionais é revelador dessa situação, ocorre durante o atendimento às ocorrências, de modo que quando um profissional faz procedimentos inadequados, ele é corrigido pelo(a) colega, mesmo quando envolve competência profissional ou procedimento normativo do serviço. Assim, o profissional pode: seguir fazendo-os, os abandonam ou os corrigem. Mas não se abre mão do objeto de disputa; já perante os pares, não se admite ter passado pela correção, ou mesmo pela "cooperação" do colega.

Torna-se visível, também, o fato de que o trabalho em equipe é uma habilidade complexa, que nem estão dispostos a integrar; 
por isso, muitas vezes, as intervenções em contexto de atendimento (quanto mais drásticas, mais elas aparecem) são feitas com um desejo de heroísmo. Os relatos mostram como é importante para qualquer profissional do SAMU ter uma participação providencial no salvamento de uma vida; e nisso o embate se coloca no meio. Por exemplo, um caso em que uma gestante foi salva de morrer enquanto dava à luz principalmente por causa da intervenção do enfermeiro, mas que foi afastado no final do atendimento pelo médico da equipe, de forma que o "encerramento" do atendimento fosse outorgado a ele.

Entre os profissionais se diz que quem entra no SAMU quer "aventura". No momento de contar o porquê escolhem esse trabalho, essa é uma afirmação; tal como colocada aqui, a fala é "[...] se veio para o SAMU é porque quer aventura". Não uma classe profissional específica ou pessoas específicas; durante a pesquisa, percebe-se que é a grande maioria que assim se coloca. Todos os dias as conversas com essa conotação aparecem; principalmente na volta de uma "ocorrência" mais difícil, quando às vezes as expressões não são de cansaço, mas de contentamento, que acompanham as falas de "[...] essa ocorrência foi muito massa! O cara estava embaixo do carro!", por exemplo. Pode-se visualizar isso também na diferenciação que fazem entre os atendimentos ou ocorrências. Assim, ao serem convocados para chamados para transferências inter-hospitalare ${ }^{16}$, os profissionais da equipe da USA se "arrastam" para a ambulância, fazem caretas e trocam os atendimentos com colegas para mudar de "vez". Por outro lado, quando se trata de um evento grave, sério, como alguns que ocorreram durante o trabalho de campo, como: tombamento de caminhão, capotamento com pessoas presas nas ferragens, paradas cardiorrespiratórias, os famosos "FAFs" e "FABs" (ferimento por arma de fogo e ferimento por arma branca) e afins, existe uma disputa entre os profissionais para atuar no atendimento. Às vezes vão duas enfermeiras por viatura, técnicos se juntam também as outras USB, e também recorrem às trocas entre colegas. Eles literalmente "se jogam" na "ocorrência", como dizem.

Em uma ocasião, depois de um longo período na "regulação", um médico soube que havia um "FAF" e pediu ao colega que o substituísse na regulação para ir ao atendimento. Ao fazer o pedido, ele disse " [...] por favor, colega, eu quero sangue!!". A impressão que se tem é que existe 
um "desejo de adrenalina", o profissional sente nesse momento que algo no trabalho envolve risco, e isso o impele a participar. No entanto, existem vários elementos que apontam para a busca por este tipo de ocorrência, dentre elas é possível citar: o desejo de atuação (de exercitar a prática médica, em razão de que na regulação isso não faz em sua plenitude), a dimensão simbólica do atendimento e o próprio heroísmo que pode resultar, como forma de escapar ao confinamento da regulação, os "trotes" que são levados a atender, dentre outros.

Nesse sentido, a interpretação sobre o trabalho no SAMU, como uma área de emoção, de "adrenalina" e de "salvar vidas" tem relação com o habitus profissional já comentado, no sentido de que, para os profissionais de saúde, sua atuação consiste em salvar vidas, lutar contra a morte, combater a desgraça, de modo que as diferenças entre profissionais dizem respeito à formação. Médico e enfermeiro estão mais vinculados a este habitus que o técnico e o condutor, mas em todos existe esse aprendizado (lembrar-se de que os condutores são socorristas, não somente condutores). Ao sentir que não estão cumprindo seu papel, os profissionais se desmotivam, e sentem que seu trabalho está sendo subutilizado ou desnecessário. Essa é uma expectativa socialmente construída, em que se espera que o profissional de saúde seja o salvador, e é a esse condicionamento que eles respondem.

Outra forma de analisar a necessidade de "adrenalina" presente no SAMU é a partir do conceito de risco-aventura de Spink (2001), que enfatiza o deslocamento moderno do sentido de risco, recuperando a aventura como positiva na gestão dos riscos ${ }^{17}$. No campo em que se está trabalhando, pode-se ver o comportamento dos profissionais como de busca do risco, uma aventura que pode ter como consequência o insucesso (a morte) ou outros perigos (contaminações, lesões físicas, atentados à segurança dos profissionais); mas isso não os impede de buscá-lo.

Spink (2001) defende que existe uma dimensão positiva do enfrentamento do risco que é inclusive histórica, e, no âmbito da saúde, vincula a dimensão simbólica com o prazer da realização profissional. As formas institucionais do enfrentamento do risco estão nas profissões que constantemente o fazem: bombeiros, detetives, policiais, e aqui, os profissionais do SAMU. Não são poucos os perigos de estar, 
simplesmente, dentro da "viatura": acidentes, colisões, objetos que se deslocam (uma enfermeira quase perdeu um dedo em uma ocasião em que a mangueira do oxigênio de soltou durante a ocorrência), ameaças da população, contaminação, entre outras. O que se pode interpretar é que o risco que é desejado pelos profissionais se imprime como uma forma de não temer o trabalho, de colocar a vida dos outros em primeiro lugar (o habitus), de crescer, de afirmar-se socialmente como um profissional indispensável.

Por isso, quando a atuação desses profissionais se distancia do

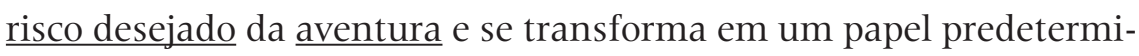
nado, no qual tem a obrigação de atender ao telefone ou participar de uma transferência porque "faz parte da sua obrigação", pode-se ter como consequência uma responsabilidade diminuída. Perrusi (2000) diz que a responsabilidade prática é uma relação entre o que os agentes interpretam sobre seu trabalho e as normas burocráticas que são estabelecidas quando eles estão inseridos em um contexto de trabalho no qual a burocracia limita de alguma forma sua atuação. Quando os procedimentos que os profissionais devem seguir chegam a eles já estabelecidos e normatizados, a interpretação que se tem é que o exercício da profissão não se realiza em sua plenitude, o que pode ser um critério de divisão do trabalho entre especialidades médicas, por exemplo. No caso do médico, o autor reforça que

[...] se a responsabilidade do médico não está diretamente dirigida ao paciente, se diversas mediações começam a surgir entre o profissional e seu cliente, a começar pela mediação técnico-administrativa [...] participar e ser agente de um sistema burocratizado dilui a responsabilidade médica [...]. (Perrusi, 2000, p. 11)

No contexto estudado, além dos elementos relacionados a essa diluição da responsabilidade médica, existem aspectos de ordem prática que conduzem e vão de encontro ao status da profissão médica, dos profissionais de saúde e do serviço: trata-se da agressão verbal que continuamente enfrentam esses profissionais por parte da população. Os profissionais comentam que, por falta de compreensão do serviço e de suas limitações, a população tende a "descontar" nos profissionais suas frustações, em particular naquele que toma as decisões nas ocorrências. 
Na prática, existe um número limitado de ambulância no município e, em determinados dias, ocorrências que extrapolam a capacidade de atendimento; nesses momentos, a tensão para os profissionais é grande, porque sabem que não podem atender mais chamados. Esse é um dos momentos relatados por eles em que a população não compreende as dificuldades, pois mesmo com essa explicação, eles são agredidos verbalmente, quando não fisicamente. Ou então quando ocorre uma pane na ambulância no momento do atendimento, como uma ocasião na qual acabou a energia para os aparelhos, e o salvamento estava em andamento; não se pode apontar a culpa disso para os profissionais, mas são eles que estavam naquele momento em uma situação bastante crítica, e a família e demais pessoas esperam uma resposta imediata. Esse, por exemplo, foi um momento bastante tenso, de medo. Assim, existe um risco formal envolvido nos atendimentos.

Existem também ameaças de processos jurídicos sobre os médicos por "negar" atendimento são substanciais - alguns já foram processados - e eles dizem que, por mais que eles saibam que devem seguir algumas regras para decidir enviar ou não uma "viatura" para um atendimento, a ameaça constante de ser processado por essa decisão acaba pressionando-os a dizer "sim" a tudo. Essa decisão tem reflexo sobre os demais profissionais que acabam fazendo o atendimento e ficam muito indignados quando "não era nada". E aí se tem mais um ponto de conflito, por cada profissional tem um lado da história, e nem todos os lados convergem.

\section{Considerações Finais}

Neste recorte analítico de uma etnografia realizada no SAMU, enfatiza-se mais especificamente as relações entre as profissões que atuam no serviço, e os conflitos decorrentes delas. A falta de compreensão da população que os profissionais sentem e relatam sobre o funcionamento do SAMU, assim como dificuldade de comunicação e entendimento do que cada profissional vive na sua rotina são causadoras de disputas, discussões e mal-estar.

Aqui foram vistos alguns elementos que afetam diretamente o trabalho, como: as expectativas sobre os atendimentos, sobre as tarefas 
e as relações; o tempo do plantão, as horas de convivência contínua com os colegas e a interação variada com a população regem o humor e a disposição para fazer os atendimentos aos "demandantes" e para a coexistência em grupo; juntamente com aspectos estruturais e simbólicos das relações entre as profissões.

Ao colocar-se sob a luz da antropologia, pode-se visualizar aquilo que não aparece "a olho nu" nas relações e práticas de saúde, e seus resultados podem inclusive ser utilizados em um plano de gestão. Propõe-se que estudos nos serviços de saúde como esse devem ser vistos como antropologia aplicada, que pode e deve ser devolvida para as coordenações dos locais para auxiliar no entendimento dos elementos constitutivos dos relacionamentos e conflitos e, assim, auxiliar na tomada de decisões estratégicas.

\section{Notas}

1 Psicóloga, Especialista em Saúde Pública, Mestre em Antropologia. Secretaria Municipal de Saúde de João Pessoa, PB. Av. Júlia Freire, s/n, Torre - João Pessoa, PB.

2 Médica, Mestre em Sociologia, Doutora em Antropologia Social. Universidade Federal da Paraíba, Conjunto Humanístico - Bloco IV. DCS/CCHLA - Campus I. Cidade Universitária. CEP: 58059900 - João Pessoa, PB.

3 Trata-se de pesquisa realizada durante o curso de mestrado no Programa de PósGraduação em Antropologia da UFPB, e a reflexão aqui apresentada expõe a parceria existente entre orientanda e orientadora para pensar as interações e as informações construídas durante o trabalho de campo. A dissertação é intitulada "'QRD à base SAMU!' Etnografia de um serviço de urgência: o SAMU - João Pessoa - PB", defendida em março de 2013.

4 Segundo a autora, existem referências, na literatura médica, sobre a demanda de atendimento nestes serviços que remontam a mais de 150 anos.

5 Dentre os estudos que abordam essa temática, encontram-se os de Knauth (2010) e Lima (2011).

6 Um estudo importante nessa área é de Armelle Giglio-Jacquemot, pesquisadora francesa que estudou atendimentos de urgência e emergência hospitalar em Marília, São Paulo, incluindo o SAMU e o Corpo de Bombeiros, nos anos de 1998 e 1999, ver Giglio-Jacquemot (2005).

7 Ednalva tem formação médica, atuando na saúde pública durante os anos de exercício, e Elisa tem formação em psicologia e atuação na saúde pública, em diversos níveis de atenção. As experiências nestes anos de prática influenciaram a problematização das questões que permeiam esta atuação, tanto focados no funcionamento dos serviços em si, como no atendimento prestado à população; uma das motivações para esta pesquisa. 
8 Termo utilizado por Fleischer (2011) com base em Scott, que significa "no palco" e "fora do palco", uma alusão à nomenclatura do teatro sobre a atuação dentro e fora dos palcos que pode utilizada como parâmetro para se pensar os processos de interação na pesquisa antropológica, caracterizada pelas fases da entrada no campo e da vivência no campo de pesquisa.

9 Expressão usada na vigilância epidemiológica da saúde, para se referir aos procedimentos de buscar os comunicantes de um evento de doença infecciosa, procurando identificar a fonte da infecção e os possíveis contatos que o doente teve e assim bloquear a dimensão e a disseminação da doença. Nesse caso, utiliza-se desse conceito para ilustrar o fato de ter ido atrás das pessoas que ainda não conhecia, de forma a aumentar o número de interlocutores.

${ }^{10}$ Um dia que Narciso voltava de caçar passou próximo a um lago e, ao inclinar-se para aplacar sua sede, viu refletida nas límpidas águas sua própria imagem. Ficou extasiado e sentiu um ardente desejo por aquele cuja imagem lhe devolvia a água, sem saber que se tratava de si mesmo. Desesperado por não poder alcançar o objeto de seu amor, que fugia das suas mãos dissolvendo-se, dizia: - Fica, peço-te, fica! Senão posso tocar-te, deixe-me pelo menos admirar-te. E assim foi definhando de paixão insatisfeita até morrer ao pé daquelas águas. Foi metamorfoseado em uma flor, o narciso, símbolo antigo da morte prematura. Tradução própria do mito de Narciso, contido no Diccionario de la mitologia griega y romana, de Martin (1996).

11 Só se teve conhecimento de que isso ocorria entre as mulheres, entre os homens não - até porque há poucos enfermeiros homens no SAMU, portanto, o repouso "superior" é basicamente médico. As questões de gênero que envolvem o campo da saúde também se reproduzem nesse contexto.

12 Conceito de Habermas (1989), que considera agir-comunicativo as interações nas quais as pessoas envolvidas se põem de acordo para coordenar seus planos de ação.

13 O conceito de habitus surgiu de uma necessidade de Bourdieu de compreender as relações entre os comportamentos dos agentes e as estruturas e condicionamento social (Setton, 2002). A partir do conceito do autor, pode-se entender as interações entre o mundo objetivo e as subjetividades individuais, porque pensar o indivíduo em termos de habitus significa afirmar que o individual, o pessoal e o subjetivo são sociais e construídos.

14 Em João Pessoa, no hall do Hospital Universitário Lauro Wanderley no qual os médicos fazem suas práticas, existe uma placa com uma frase célebre do professor: "O médico é o reflexo de Deus na esperança de quem sofre".

15 Atualmente, isso pode ser fortemente evidenciado no Brasil com a discussão da sanção com vetos da presidente da Lei do Ato Médico (Lei n. 12.842).

$16 \mathrm{O}$ transporte inter-hospitalar refere-se à transferência de pacientes entre unidades não hospitalares ou hospitalares de atendimento às urgências e emergências, que funcionem como bases de estabilização para pacientes graves, de caráter público ou privado. (Brasil, 2002)

17 Como elemento dessa análise, a autora traz a tipificação de risco de Machlis e Rosa (apud Spink, 2001), que usam a expressão risco desejado para referir-se àquelas atividades que supõem incertezas quanto aos seus resultados e suas consequências; e são exatamente estas incertezas que impelem os sujeitos a realizá-las, por isso são desejadas. 


\section{Referências}

ALMEIDA, Paulo J. S. O conflito no processo de trabalho da equipe de emergência. Dissertação (mestrado) - Universidade Federal de Santa Catarina. Florianópolis, 2007.

BACHELARD, Gaston. A formação do espírito científico. Rio de Janeiro: Contraponto, 1996.

BOURDIEU, Pierre. Algumas propriedades dos campos: exposição feita na Ecole Normale Supérieure. 1976. Disponível em: <http://www.scribd. com/doc/88886722/Algumas-Propriedades-Dos-Campos-Pierre-Bourdieu $>$. Acesso em: 22 ago. 2012.

BOURDIEU, Pierre. Homo academicus. Buenos Aires: Siglo XXI Editores, 2008.

BRANDÃO, Carlos R. Reflexões sobre como fazer trabalho de campo.

Sociedade e Cultura, v. 10, n. 1, 2007.

BRASIL. Ministério da Saúde. Portaria GM n. 2.048. Brasília, DF:

Ministério da Saúde, 2002.

CLIFFORD, James. A experiência etnográfica: antropologia e literatura no século XX. Rio de Janeiro: Ed. UFRJ, 1998.

COIMBRA, Cecília; LEITÃO, Maria Beatriz. Das essências às

multiplicidades: especialismo psi e produções de subjetividades.

Psicologia \& Sociedade, v. 15, n. 2, jul.-dez. 2003.

CONSORTE, Josildeth. A morte na prática médica. In: MARTINS, J. S.

A morte e os mortos na sociedade brasileira. São Paulo: Hucitec, 1983.

DAMATTA, Roberto. O ofício do etnólogo, ou como ter "Anthropological Blues". In: NUNES, Edson de Oliveira. A Aventura Sociológica. Rio de Janeiro: Zahar, 1978.

FLEISCHER, Soraya. Parteiras, buchudas e aperreios: uma etnografia do atendimento obstétrico não oficial em Melgaço, Pará. Belém: Paka-Tatu; Santa Cruz do Sul: EDUNISC, 2011.

FOUCAULT, Michel. Microfísica do poder. 27. ed. Rio de Janeiro: Edições Graal, 2009.

FREIDSON, Elliot. Profissão médica: um estudo de sociologia do conhecimento aplicado São Paulo: Editora UNESP; Porto Alegre: Sindicato dos Médicos, 2009.

GIGLIO-JACQUEMOT, A. Urgências e emergências em saúde: perspectivas de profissionais e usuários. Rio de Janeiro: Editora FIOCRUZ, 2005.

GOFFMAN, Erving. Estigma. La identidad deteriorada. Buenos Aires: Amorrortu, 1970. 
HABERMAS, Jürgen. Consciência moral e agir comunicativo. Rio de Janeiro: Tempo Brasileiro; 1989.

HELMAN, Cecil G. Cultura, saúde e doença. 4. ed. Porto Alegre: Artmed, 2003.

KNAUTH, D. A etnografia na saúde coletiva: desafios e perspectivas. In: SCHUCH, P.; VIEIRA, M. S; PETERS, R. Experiências, dilemas e desafios do fazer etnográfico contemporâneo. Porto Alegre: UFRGS, 2010.

LIMA, D. A. C. A. Etnografia do serviço de saúde: uma análise antropológica do cotidiano e das práticas de saúde do Centro de Testagem e Aconselhamento de João Pessoa - PB. 80f. Monografia - Universidade Federal da Paraíba. João Pessoa, 2011.

MACHADO, Maria Helena. Profissões de saúde: uma abordagem sociológica. Rio de Janeiro: FIOCRUZ, 1995.

MALINOWSKI, Branislaw. Argonautas do Pacífico Ocidental. São Paulo: Abril Cultural, 1984.

MARTIN, René. Diccionario de la mitologia griega y romana. Madrid: Editorial Espasa Calpe, 1996.

PERRUSI, Artur. Profissão, vocação e medicina. Revista Política $\boldsymbol{\delta}$ Trabalho, n. 16, p. 73-84, 2000.

RODRIGUES, Patricia F.; ALVARO, Alex L.T.; RONDINA, Regina. Sofrimento no trabalho na visão de Dejours. Revista Científica Eletrônica de Psicologia, v. 4, n. 7, 2006.

SASSI, André P. Formação identitária dos estudantes de medicina: novo currículo, novas identidades? Dissertação (Mestrado) - Universidade Federal da Paraíba. João Pessoa, 2012.

SARTI, Cynthia. Corpo e doença no trânsito de saberes. RBCS, v. 25, n. 74, 2010.

SETTON, Maria G. J. A teoria do habitus em Pierre Bourdieu: uma leitura contemporânea. Revista Brasileira de Educação, n. 20, 2002.

SPINK, Mary J.P. Trópicos do discurso sobre risco: risco-aventura como metáfora na modernidade tardia. Caderno de Saúde Pública, v. 17, n. 6, nov.-dez. 2001.

VÍCTORA, Ceres G.; KNAUTH, Daniela R.; HASSEN, Maria N. A. Pesquisa qualitativa em saúde: uma introdução ao tema. Porto Alegre: Tomo Editorial, 2000.

Recebido em 11/06/2013

Aceito em 01/09/2014 